\title{
RANCANG BANGUN SISTEM PAKAR MENDIAGNOSA PENYAKIT OBSESSIVE COMPULSIVE DISORDER DENGAN METODE DEMPSTER SHAFER
}

\author{
Nidia Enjelita Saragih ${ }^{1}$, Robiatul Adawiyah ${ }^{2}$ \\ Universitas Potensi Utama \\ ${ }^{1}$ nidia.1924@gmail.com, ${ }^{2}$ robiatulbintisyarifuddin@gmail.com
}

\begin{abstract}
Anxiety is a normal reaction to stress and can be beneficial in some situations. It can alert us to dangers and help us prepare and pay attention. Anxiety disorders differ from normal feelings of nervousness or anxiousness, and involve excessive fear or anxiety. Anxiety disorders can cause people into try to avoid situations that trigger or worsen their symptoms. There are several types of anxiety disorders, including Obsessive Compulsive Disorder. Obsessive Compulsive Disorder (OCD) is a disorder in which people have recurring, unwanted thoughts, ideas or sensations (obsessions) that make them feel driven to do something repetitively (compulsions). The repetitive behaviors, such as hand washing, checking on things or cleaning, can significantly interfere with a person's daily activities and social interactions. This Expert system which implement Dempster Shafer Method can help anyone to make sure that they have OCD and need psichologist help to prevent this distress becoming worst.
\end{abstract}

\section{Keywords: Anxiety Disorder, Obsessive Compulsive Disorder, Expert System, Dempster Shafer}

\section{PENDAHULUAN}

Obsessive Compulsive Disorder adalah sebuah gangguan kejiwaan yang merupakan kumpulan dari dua sikap utama yakni obsesif dan kompulsif. Obsesif adalah sikap dan pemikiran yang berulang menguasai individu tanpa dapat terkendalikan, sedangkan kompulsif adalah dorongan yang tidak tertahankan bagi individu untuk melakukan sesuatu. Gangguan mental ini merupakan gejala kegelisahan yang luar biasa. Penyandang Obsessive Compulsive Disorder akan menampakkan gejala berupa sikap sikap berlebihan dalam kehidupan sehari-hari. Individu yang mengalami obsessive compulsive disorder juga diketahui sering menyembunyikan gejala mereka. Rasa malu membuat individu yang mengalami obsessive compulsive disorder berusaha untuk menyembunyikan gejala mereka sehingga menyebabkan keterlambatan diagnosa dan pengobatan.

Banyaknya pasien yang mencoba merahasiakan kondisi mereka, membuat individu gagal mencari dan mendapat pengobatan yang tepat (National Institute of Mental Health, 2016). Hal lain yang membuat mereka sering menyembunyikan gejala dan kondisi mereka pada orang lain adalah karena adanya stigma yang mengatakan obsessive compulsive disorder sebagai penyakit mental ,hal ini membuat mereka khawatir terjadi penolakan dan penghakiman atas perilakunya. Banyaknya individu yang mengalami obsessive compulsive disorder hidup dengan menyembunyikan kondisi mereka, membuat psikolog atau psikiater, keluarga dan orang sekitar mereka sulit mengetahui masalah yang mereka hadapi (National Institute of Mental Health, 2016).

Sikap penderita yang justru menyembunyikan kondisi mereka ini membawa banyak efek negative seperti keterlambatan diagnosa, pengobatan, gagal mencari dan mendapat pengobatan, resisten dengan pengobatan, kekhawatiran berlebihan karena takut terjadi penolakan oleh orang sekitar, terisolasi dan memiliki kualitas hidup yang negative. Untuk mencegah keterlambatan diagnosa dan penanganan terhadap OCD dibutuhkan sebuah sistem yang mampu mendiagnosa keberadaan penyakit tersebut. Sistem tersebut akan bekerja selayaknya seorang dokter dalam mendiagnosa penyakit. Sistem yang dimaksud adalah sistem pakar yang berusaha mengadopsi pengetahuan manusia ke dalam komputer agar dapat menyelesaikan masalah seperti yang biasa dilakukan oleh pakar. Ada banyak metode yang dikenal dalam mengimplementasikan keahlian seorang pakar ke dalam sistem, salah satunya adalah Dempster Shafer. Metode Dempster Shafer adalah representasi, kombinasi dan propogasi ketidakpastian, dimana teori ini memiliki beberapa karakteristik yang secara instutitif sesuai dengan cara berfikir seorang pakar, namun dasar matematika yang kuat. Metode ini memberikan ruang pada pakar dalam memberikan nilai kepercayaan pada pengetahuan yang diungkapkannya.

\section{KAJIAN LITERATURE \\ Sistem pakar}

Secara umum, sistem pakar (expert system) adalah sistem yang berusaha mengadopsi pengetahuan manusia ke komputer, agar komputer dapat menyelesaikan masalah seperti yang biasa dilakukan oleh para ahli. Sistem pakar yang baik dirancang agar dapat menyelesaikan suatu permasalahan tertentu dengan meniru kerja dari para ahli.

Harapannya, orang biasa pun akan dapat menyelesaikan permasalahan yang dianggap cukup rumit yang tadinya hanya dapat diselesaikan oleh seorang pakar. Juga, terkadang seorang pakar tidak dapat melayani secara penuh karena terbatasnya waktu dan banyaknya hal yang harus dilayani sehingga sangat dibutuhkan sebuah sistem yang dapat menggantikan peran pakar tersebut.

\section{Metode Dempster-Shafer}

Metode Dempster-Shafer pertama kali diperkenalkan oleh Dempster, yang melakukan percobaan model ketidakpastian dengan range probabilities dari pada sebagai probabilitas tunggal. Kemudian pada tahun 1976 Shafer mempublikasikan teori Dempster itu pada sebuah 
buku yang berjudul Mathematical Theory Of Evident. Dempster-Shafer Theory Of Evidence, menunjukkan suatu cara untuk memberikan bobot kenyakinan sesuai fakta yang dikumpulkan.

Secara umum teori Dempster-Shafer ditulis dalam suatu interval: [Belief,Plausibility]. Belief (Bel) adalah ukuran kekuatan evidence dalam mendukung suatu himpunan proposisi. Jika bernilai 0 maka mengindikasikan bahwa tidak ada evidence, dan jika bernilai 1 menunjukkan adanya kepastian. Plausibility (Pls) akan mengurangi tingkat kepastian dari evidence. Plausibility bernilai 0 sampai 1 . Jika yakin akan X', maka dapat dikatakan bahwa $\operatorname{Bel}\left(X^{\prime}\right)=1$, sehingga rumus di atas nilai $\operatorname{dari} \operatorname{Pls}(\mathrm{X})=0$.

Menurut Giarratano dan Riley fungsi Belief dapat diformulasikan dan ditunjukkan pada persamaan (1) :

$$
\operatorname{Bel}(X)=\sum_{Y \subseteq X} m(Y)
$$

Dan Plausibility dinotasikan pada persamaan (2):

$$
\text { Pls }(X)=1-\operatorname{Bel}(X)=1-\sum_{Y \subseteq X} m(X)
$$

dimana :

$\operatorname{Bel}(\mathrm{X})=\operatorname{Belief}(\mathrm{X})$

Pls $(\mathrm{X})=$ Plausibility $(\mathrm{X})$

$\mathrm{m}(\mathrm{X})=$ mass function $\operatorname{dari}(\mathrm{X})$

$\mathrm{m}(\mathrm{Y})=$ mass function $\operatorname{dari}(\mathrm{Y})$

Teori Dempster-Shafer menyatakan adanya frame of discrement yang dinotasikan dengan simbol $(\Theta)$. frame of discrement merupakan semesta pembicaraan dari sekumpulan hipotesis sehingga sering disebut dengan environment yang ditunjukkan pada persamaan (3) :

Dimana :

$$
\Theta=\{\theta 1, \theta 2, \ldots \theta \mathrm{N}\}
$$

\section{$\Theta=$ frame of discrement atau environment}

$\theta 1, \ldots, \theta \mathrm{N}=$ element/ unsur bagian dalam environment

Environment mengandung elemen-elemen yang menggambarkan kemungkinan sebagai jawaban, dan hanya ada satu yang akan sesuai dengan jawaban yang dibutuhkan. Kemungkinan ini dalam teori DempsterShafer disebut dengan power set dan dinotasikan dengan $\mathrm{P}$ $(\Theta)$, setiap elemen dalam power set ini memiliki nilai interval antara 0 sampai 1.

$$
\mathrm{m}: \mathrm{P}(\Theta)[0,1]
$$

Sehingga dapat dirumuskan pada persamaan (4) :

$$
\sum_{X \in P(\Theta)} m(X)=1
$$

Dengan :

$\mathrm{P}(\Theta)=$ power set

$\mathrm{m}(\mathrm{X})=$ mass function $(\mathrm{X})$

Mass function (m) dalam teori Dempster-shafer adalah tingkat kepercayaan dari suatu evidence (gejala), sering disebut dengan evidence measure sehingga dinotasikan dengan (m).

Tujuannya adalah mengaitkan ukuran kepercayaan elemen-elemen $\theta$. Tidak semua evidence secara langsung mendukung tiap-tiap elemen. Untuk itu perlu adanya probabilitas fungsi densitas (m). Nilai m tidak hanya mendefinisikan elemen-elemen $\theta$ saja, namun juga semua subsetnya. Sehingga jika $\theta$ berisi n elemen, maka subset $\theta$ adalah $2 n$. Jumlah semua $\mathrm{m}$ dalam subset $\theta$ sama dengan 1 . Apabila tidak ada informasi apapun untuk memilih hipotesis, maka nilai :

$$
\mathrm{m}\{\theta\}=1,0
$$

Apabila diketahui $\mathrm{X}$ adalah subset dari $\theta$, dengan $\mathrm{m} 1$ sebagai fungsi densitasnya, dan Y juga merupakan subset dari $\theta$ dengan $\mathrm{m} 2$ sebagai fungsi densitasnya, maka dapat dibentuk fungsi kombinasi $\mathrm{m} 1$ dan $\mathrm{m} 2$ sebagai $\mathrm{m} 3$, yaitu ditunjukkan pada persamaan (5)

$$
\mathrm{m} 3(\mathrm{Z})=\frac{\Sigma_{\mathrm{X} \cap \mathrm{Y}=2} \mathrm{~m}_{1}(\mathrm{X}) \cdot \mathrm{m}_{2}(\mathrm{Y})}{1-\Sigma_{\mathrm{X} \cap \mathrm{Y}=\mathrm{o}} \mathrm{ml}(\mathrm{X}) \cdot \mathrm{m} 2(\mathrm{Y})}
$$

dimana :

$\mathrm{m} 3(\mathrm{Z})=$ mass function dari evidence $(\mathrm{Z})$

$\mathrm{m} 1(\mathrm{X})=$ mass function dari evidence $(\mathrm{X})$, yang diperoleh dari nilai keyakinan suatu evidence dikalikan dengan nilai disbelief dari evidence tersebut.

$\mathrm{m} 2(\mathrm{Y})=$ mass function dari evidence $(\mathrm{Y})$, yang diperoleh dari nilai keyakinan suatu evidence dikalikan dengan nilai disbelief dari evidence tersebut.

\section{Obsessive Compulsive Disorder}

Obsessive Compulsive Disorder adalah sebuah gangguan kejiwaan yang merupakan kumpulan dari dua sikap utama yakni obsesif dan kompulsif. Obsesif adalah sikap dan pemikiran yang berulang menguasai individu tanpa dapat terkendalikan, sedangkan kompulsif adalah dorongan yang tidak tertahankan bagi individu untuk melakukan sesuatu.

Studi yang mendalam mengenai ObsessiveCompulsive Disorder (OCD) di Indonesia, bisa dikatakan belum ada. Namun, kenyataannya di masyarakat, laporan mengenai orang yang memiliki beberapa ciri-ciri OCD, menunjukkan adanya eksistensi gangguan tersebut.

Kecemasan dan perasaan yang dimunculkan oleh obsesi dapat menekan penderita (distress) sehingga mereka berusaha mencari strategi yang dapat membuat mereka merasa lebih baik. Strategi ini, bisa berupa kompulsi, atau ritual yang ditujukan untuk menurunkan distress yang dirasakannya. (Lia Syafaatul, 2017)

Banyaknya pasien yang mencoba merahasiakan kondisi mereka, membuat individu gagal mencari dan mendapat pengobatan yang tepat (National Institute of Mental Health, 2016), bahkan dalam beberapa kasus yang lebih ekstrem, individu menjadi resisten terhadap pengobatan karena terus menerus menyembunyikan kondisi mereka (Mishra, 2007). Hal lain yang membuat mereka sering menyembunyikan gejala dan kondisi mereka pada orang lain adalah karena adanya stigma yang mengatakan obsessive compulsive disorder sebagai penyakit mental (Corrigan, Roe, \& Tsang, 2011), hal ini membuat mereka khawatir terjadi penolakan dan penghakiman atas perilakunya. Banyaknya individu yang mengalami obsessive compulsive disorder hidup dengan menyembunyikan kondisi mereka, membuat psikolog atau psikiater, keluarga dan orang sekitar mereka sulit mengetahui masalah yang mereka hadapi (National Institute of Mental Health, 2016). 


\section{METODE PENELITIAN}

Metodologi penelitian akan sangat membantu penulis dalam proses kerja penyelesaian masalah. Langkahlangkah yang dilakukan dalam menyelesaikan persoalan yang dijelaskan di atas, dapat dijelaskan dengan kerangka berikut :

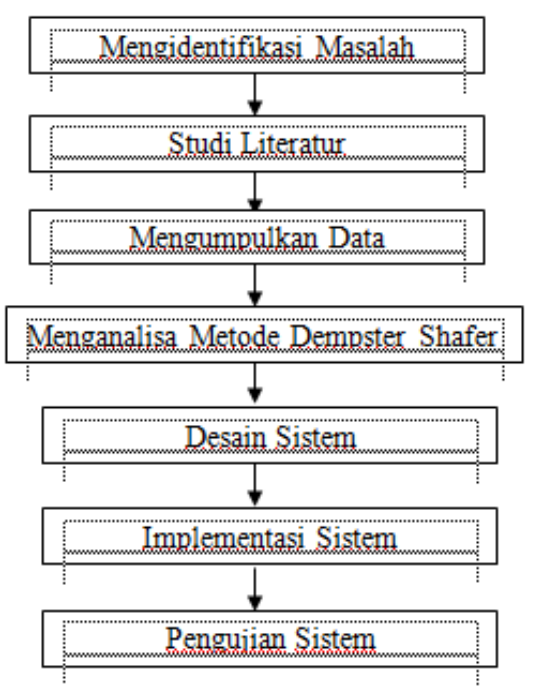

Gambar 1. Kerangka Penelitian

Berdasarkan kerangka pada gambar di atas maka masingmasing langkah dapat diuraikan sebagai berikut:

1. Mengidentifikasi Masalah

Ruang lingkup masalah yang diteliti harus ditentukan terlebih dahulu karena tahapan identifikasi masalah dimulai dengan menentukan rumusan masalah dan tujuan dari dilakukannya penelitian.

2. Mempelajari Literatur

Studi literatur ini bertujuan untuk mengetahui metode dan dasar-dasar ilmu pengetahuan ataupun referensi yang mendukung bagi pembangunan sistem pakar.

Studi pustaka meliputi : 1) Sistem Pakar, 2) Metode Dempster Shafer. Diperlukan literatur yang berguna untuk pemahaman konsep dan pendalaman teori tentang sistem pakar menggunakan metode Dempster Shafer dari beberapa sumber jurnal internasional, buku-buku dan internet.

3. Pengumpulan Data

Data yang digunakan berasal dari data-data gejala yang sesuai dengan kriteria yang dibutuhkan. Dimana data didapatkan dari wawancara dengan psikolog dan dilengkapi dengan sumber lainnya.

4. Menganalisa Metode Dempster Shafer

Metode yang digunakan dalam pembangunan sistem ini adalah metode Dempster Shafer yang dimulai dari melakukan pengumpulan data gejala kemudian menentukan nilai kepercayaan (belief) dari masing-masing evidence untuk bisa diimplementasikan ke dalam persamaan sehingga menghasilkan nilai presentasi kesimpulan dari diagnosa OCD berdasarkan pengetahuan yang didapatkan dari pakar.

5. Desain Sistem

Desain sistem adalah sebuah media yang berfungsi menghubungkan pengguna dengan sistem. Pada tahap ini user interface dirancang agar pengguna dapat cepat menguasai cara penggunaan sistem, interaktif, dan user friendly.

6. Implementasi Sistem

Sesuai dengan pengolahan data maka pada tahap implementasi dilakukan pengimplementasian ke sistem yang telah dirancang.

7. Pengujian Sistem

Tahap akhir penyerapan pengetahuan pada sistem pakar ini adalah tahap uji coba sistem. Skenario pengujian yang akan dilakukan adalah dengan menyesuaikan hasil dari sistem dengan perhitungan manual.

\section{HASIL DAN PEMBAHASAN \\ Basis Pengetahuan}

Basis pengetahuan merupakan kumpulan data-data yang digunakan pada penelitian sistem pakar ini. Basis pengetahuan tersebut berisikan data-data tentang jenis penyakit, gejala-gejala, dan relasi gejala dengan penyakit. Sistem pakar untuk mendiagnosis penyakit Obsessive Compulsive ini diperoleh dari Psikolog berdasarkan gejala umum dari pengalaman pakar.

Berdasarkan data yang diperoleh, ada 3 jenis Obsessive Compulsive Disorder yang mungkin diderita oleh seseorang. Ketiganya bisa dilihat pada tabel berikut .

Tabel 1. Klasifikasi Obsessive Compulsive disorder

\begin{tabular}{|l|l|l|}
\hline No & Nama Tipe & Kode \\
\hline 1 & Washing & W \\
\hline 2 & Ordering & O \\
\hline 3 & Checking & C \\
\hline
\end{tabular}

Adapun data gejala pada masing-masing tipe Obsessive Compulsive Disorder di atas, tertera pada table berikut.

Tabel 2. Data Gejala dan Penyakit

\begin{tabular}{|c|c|c|c|c|}
\hline \multirow{2}{*}{$\begin{array}{c}\text { K } \\
\text { o } \\
\text { de }\end{array}$} & \multirow[t]{2}{*}{ Gejala } & \multicolumn{3}{|c|}{ Nilai Bobot } \\
\hline & & $\begin{array}{l}\text { Wash } \\
\text { ing } \\
\text { (W) }\end{array}$ & $\begin{array}{l}\text { Order } \\
\text { ing } \\
(\mathbf{O})\end{array}$ & $\begin{array}{l}\text { Chec } \\
\text { king } \\
\text { (C) }\end{array}$ \\
\hline $\begin{array}{l}\mathrm{G} \\
01\end{array}$ & $\begin{array}{lr}\text { Muncul dorongan untuk } \\
\text { melakukan } & \text { suatu } \\
\text { kegiatan } & \text { berulang- } \\
\text { ulang. } & \\
\end{array}$ & 0.8 & 0.8 & 0.8 \\
\hline $\begin{array}{l}\mathrm{G} \\
02\end{array}$ & $\begin{array}{l}\text { Terganggunya rutinitas } \\
\text { normal }\end{array}$ & 0.8 & 0.8 & 0.8 \\
\hline $\begin{array}{c}\mathrm{G} \\
03\end{array}$ & $\begin{array}{l}\text { Memburuknya } \\
\text { hubungan sosial }\end{array}$ & 0.6 & 0.6 & 0.6 \\
\hline $\begin{array}{l}\mathrm{G} \\
04\end{array}$ & $\begin{array}{l}\text { Munculnya dorongan, } \\
\text { kekhawatiran, dan } \\
\text { bayangan-bayangan } \\
\text { yang terus mengganggu } \\
\text { yang menyebabkan } \\
\text { kegelisahan }\end{array}$ & 0.8 & 0.8 & 0.8 \\
\hline $\begin{array}{l}\mathrm{G} \\
05\end{array}$ & \begin{tabular}{llr}
\multicolumn{2}{l}{ Kecemasan } & yang \\
muncul berasal dari \\
dalam diri, bukan \\
pengaruh dari luar
\end{tabular} & 0.8 & 0.8 & 0.8 \\
\hline $\begin{array}{l}\mathrm{G} \\
06\end{array}$ & $\begin{array}{l}\text { Tidak sedang berada di } \\
\text { bawah pengaruh obat- } \\
\text { obatan }\end{array}$ & 0.8 & 0.8 & 0.8 \\
\hline
\end{tabular}




\begin{tabular}{|c|c|c|c|c|}
\hline G07 & $\begin{array}{l}\text { Berusaha menekan atau } \\
\text { menghilangkan } \\
\text { gangguan kecemasan } \\
\text { dengan melakukan } \\
\text { kegiatan berulang }\end{array}$ & 0.8 & 0.8 & 0.8 \\
\hline G08 & $\begin{array}{l}\text { Perbuatan berulang } \\
\text { yang dilakukan bukan } \\
\text { untuk memperoleh } \\
\text { kepuasan. Tetapi hanya } \\
\text { untuk mengurangi } \\
\text { penderitaan akibat rasa } \\
\text { cemas yang terus } \\
\text { muncul }\end{array}$ & 0.8 & 0.8 & 0.8 \\
\hline G09 & $\begin{array}{l}\text { Menghabiskan waktu } \\
\text { lebih dari satu jam } \\
\text { untuk melakukan hal } \\
\text { yang berulang }\end{array}$ & 0.8 & 0.8 & 0.8 \\
\hline G10 & $\begin{array}{l}\text { Berusaha menghindari } \\
\text { tempat-tempat yang } \\
\text { memicu munculnya } \\
\text { obsesi (misalnya } \\
\text { menghindari berjabat } \\
\text { tangan, menghindari ke } \\
\text { toilet umum). }\end{array}$ & 0.8 & 0.4 & 0.4 \\
\hline G11 & $\begin{array}{l}\text { Muncul dorongan } \\
\text { agresif yang } \\
\text { mengerikan( misalnya } \\
\text { melukai anak-anak atau } \\
\text { berteriak di tempat } \\
\text { ibadah) }\end{array}$ & 0.2 & 0.2 & 0.2 \\
\hline G12 & $\begin{array}{l}\text { Muncul kebutuhan } \\
\text { untuk memastikan } \\
\text { segala benda dalam } \\
\text { kondisi } \\
\text { khusus(misalnya } \\
\text { susunan benda mesti } \\
\text { simetris, berjumlah } \\
\text { genap, dan kondisi } \\
\text { khusus lainnya) }\end{array}$ & 0 & 0.8 & 0.5 \\
\hline G13 & $\begin{array}{l}\text { Meyakini bahwa } \\
\text { dirinya terkontaminasi } \\
\text { oleh orang lain }\end{array}$ & 0.8 & 0.3 & 0 \\
\hline G14 & $\begin{array}{l}\text { Terus menerus } \\
\text { mencuci tangan }\end{array}$ & 0.8 & 0 & 0 \\
\hline G15 & $\begin{array}{l}\text { Terus-menerus } \\
\text { mengecek saluran gas }\end{array}$ & 0 & 0 & 0.8 \\
\hline G16 & $\begin{array}{l}\text { Terus-menerus } \\
\text { mengecek kunci pintu }\end{array}$ & 0 & 0 & 0.8 \\
\hline G17 & $\begin{array}{l}\text { Mengecek suatu } \\
\text { pekerjaan secara } \\
\text { berulang }\end{array}$ & 0 & 0 & 0.8 \\
\hline G18 & $\begin{array}{l}\text { Berpikir bahwa } \\
\text { tangannya tetap kotor } \\
\text { meski dicuci berkali- } \\
\text { kali }\end{array}$ & 0.8 & 0 & 0 \\
\hline G19 & $\begin{array}{l}\text { Ragu apakah pintu } \\
\text { rumah ditinggalan } \\
\text { terbuka }\end{array}$ & 0 & 0 & 0.8 \\
\hline G20 & $\begin{array}{l}\text { Ragu telah mematikan } \\
\text { Kompor }\end{array}$ & 0 & 0 & 0.8 \\
\hline
\end{tabular}

Tabel 3 merupakan basis pengetahuan relasi gejala dan penyakit yang mendukung diagnosa penyakit Obsessive Compulsive Disorder.
Tabel 3 Basis Pengetahuan Relasi

\begin{tabular}{|c|c|c|c|}
\hline \multirow{2}{*}{$\begin{array}{c}\text { Kode } \\
\text { Gejala }\end{array}$} & \multicolumn{3}{|c|}{ Kode Penyakit } \\
\cline { 2 - 4 } & $\begin{array}{c}\text { Washing } \\
\text { (W) }\end{array}$ & $\begin{array}{c}\text { Ordering( } \\
\text { O) }\end{array}$ & $\begin{array}{c}\text { Checking } \\
\text { (C) }\end{array}$ \\
\hline G01 & $\checkmark$ & $\checkmark$ & $\checkmark$ \\
\hline G02 & $\checkmark$ & $\checkmark$ & $\checkmark$ \\
\hline G03 & $\checkmark$ & $\checkmark$ & $\checkmark$ \\
\hline G04 & $\checkmark$ & $\checkmark$ & $\checkmark$ \\
\hline G05 & $\checkmark$ & $\checkmark$ & $\checkmark$ \\
\hline G06 & $\checkmark$ & $\checkmark$ & $\checkmark$ \\
\hline G07 & $\checkmark$ & $\checkmark$ & $\checkmark$ \\
\hline G08 & $\checkmark$ & $\checkmark$ & $\checkmark$ \\
\hline G09 & $\checkmark$ & $\checkmark$ & $\checkmark$ \\
\hline G10 & $\checkmark$ & $\checkmark$ & $\checkmark$ \\
\hline G11 & $\checkmark$ & $\checkmark$ & $\checkmark$ \\
\hline G12 & - & $\checkmark$ & $\checkmark$ \\
\hline G13 & $\checkmark$ & $\checkmark$ & - \\
\hline G14 & $\checkmark$ & - & - \\
\hline G15 & - & - & $\checkmark$ \\
\hline G16 & - & - & $\checkmark$ \\
\hline G17 & - & - & $\checkmark$ \\
\hline G18 & $\checkmark$ & - & - \\
\hline G19 & - & - & $\checkmark$ \\
\hline G20 & - & - & $\checkmark$ \\
\hline
\end{tabular}

\section{Diagram Keputusan}

Diagram keputusan digunakan untuk mempermudah menggambarkan aturan yang ada dalam sistem. Diagram keputusan pada sistem pakar ini digambarkan dalam Gambar 2. Pada gambar tersebut menjelaskan tentang gejala-gejala yang merujuk pada tipe OCD yang diderita. Sehingga dapat diambil kesimpulan masing-masing.

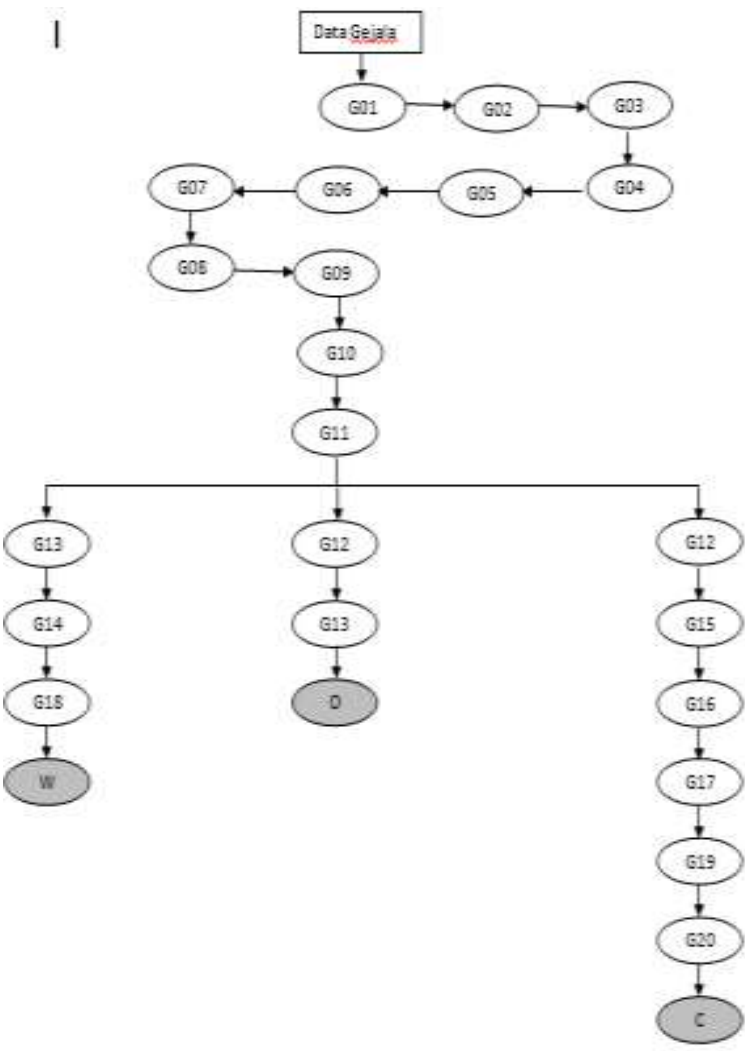

Gambar 2. Diagram Keputusan Sistem Pakar 


\section{Penerapan Metode Dempster Shafer Dalam Proses Penelusuran}

Untuk menghitung nilai Dempster Shafer(DS) penyakit Obsessive Compulsive Disorder yang dipilih dengan menggunakan nilai believe yang telah ditentukan pada setiap gejala.

$$
\operatorname{Pl}(\Theta)=1-\mathrm{Bel}
$$

Dimana nilai bel (believe) merupakan nilai bobot yang diinput oleh pakar.

Misalkan seorang pasien memiliki gejala : Muncul kebutuhan untuk memastikan segala benda dalam kondisi khusus, berpikir bahwa tangannya tetap kotor, dan terus menerus mencuci tangan.

Gejala 1 : Muncul kebutuhan untuk memastikan segala benda dalam kondisi khusus(G12).

$$
\begin{array}{ll}
\mathrm{m} 1\{\mathrm{O}, \mathrm{C}\} & =0.8 \\
\Theta & =1-0,8 \\
& =0.2
\end{array}
$$

Gejala 2 : Berpikir bahwa tangannya tetap kotor(G18)

$$
\begin{array}{ll}
\mathrm{m} 2\{\mathrm{~W}\} & =0.8 \\
\Theta & =1-0,8 \\
& =0.2
\end{array}
$$

Dengan munculnya 2 gejala di atas, maka harus dilakukan penghitungan densitas baru untuk beberapa kombinasi (m3). Untuk memudahkan perhitungan maka himpunanhimpunan bagian yang terbentuk dimasukkan ke dalam tabel. Kolom pertama diisi dengan gejala yang pertama (m1). Sedangkan baris pertama diisi dengan gejala yang kedua $(\mathrm{m} 2)$. Sehingga diperoleh nilai $\mathrm{m}_{3}$ sebagai hasil kombinasi $\mathrm{m} 1$ dan $\mathrm{m} 2$.

Tabel 4. Aturan Kombinasi m3

\begin{tabular}{|ll|ll|ll|}
\hline & & $\{\mathrm{W}\}$ & 0.8 & $\Theta$ & 0.2 \\
\hline$\{\mathrm{O}, \mathrm{C}\}$ & 0.8 & $\Theta$ & 0.64 & $\{\mathrm{O}, \mathrm{C}\}$ & 0.16 \\
\hline$\Theta$ & 0.2 & $\{\mathrm{~W}\}$ & 0.16 & $\Theta$ & 0.04 \\
\hline
\end{tabular}

Karena tidak adanya irisan antara $\{\mathrm{P} 1, \mathrm{P} 4\}$ dan $\{\mathrm{P} 2\}$ maka diperoleh $\{\Theta\}$ pada baris kedua kolom kedua dan nilainya diperoleh dari $0,2 \times 0,4$. Demikian pula $\{P 2\}$ pada baris kedua kolom ketiga merupakan irisan antara $\{\mathrm{P} 2\}$ baris kedua kolom pertama dengan $\{\Theta\}$ pada baris pertama kolom ketiga dan nilainya diperoleh dari 0,8 x 0.4 . Sehingga dapat dihitung.

$$
\begin{aligned}
& \mathrm{m} 3(0, C)=\frac{0.16}{1-0.64}=0.44 \\
& \mathrm{~m} 3(\mathrm{~W})=\frac{0.16}{1-0.64}=0.44 \\
& \mathrm{~m} 3(\theta)=\frac{0.04}{1-0.64}=0.111
\end{aligned}
$$

Jika kemudian terdapat gejala lain yaitu : terus menerus mencuci tangan (m4 $\{\mathrm{W}\}$ ), maka harus dilakukan perhitungan untuk densitas baru m5. Untuk memudahkan perhitungan maka himpunan-himpunan akan dibuat ke dalam bentuk tabel. Kolom pertama berisi semua himpunan bagian pada $\mathrm{m} 3$ sebagai fungsi densitas. Sedangkan baris pertama berisi semua himpunan bagian pada gejala terus menerus mencuci tangan dengan $\mathrm{m} 4$ sebagai fungsi densitas. Sehingga diperoleh nilai $\mathrm{m} 5$ sebagai hasil m kombinasi

$$
\begin{aligned}
& \mathrm{m} 4\{\mathrm{~W}\}=0,8 \\
& \mathrm{~m}(\Theta)=1-0,8=0,2
\end{aligned}
$$

Tabel 5. Aturan Kombinasi m5

\begin{tabular}{|cc|cc|cc|}
\hline \multicolumn{7}{|c|}{} & & $\{\mathrm{W}\}$ & 0.8 & $\Theta$ & 0.2 \\
\hline$\{\mathrm{O}, \mathrm{C}\}$ & 0.444 & $\Theta$ & 0.355 & $\{\mathrm{O}, \mathrm{C}\}$ & 0.088 \\
\hline$\{\mathrm{W}\}$ & 0.444 & $\{\mathrm{~W}\}$ & 0.355 & $\{\mathrm{~W}\}$ & 0.088 \\
\hline$\Theta$ & 0.111 & $\{\mathrm{~W}\}$ & 0.088 & $\Theta$ & 0.022 \\
\hline
\end{tabular}

Sehingga dapat dihitung :

$$
\begin{gathered}
\mathrm{m} 5(\mathrm{O}, \mathrm{C})=\frac{0.088}{1-0.355}=0.136 \\
\mathrm{~m} 5(\mathrm{~W})=\frac{0.088+0.088+0.352}{1-0.355}=0.818 \\
\mathrm{~m} 5(\theta)=\frac{0.022}{1-0.355}=0.033
\end{gathered}
$$

Berdasarkan langkah-langkah diatas maka dapat disimpulkan nilai densitas (m) baru sesuai gejala baru.

Tabel 6. Kesimpulan dalam menentukan nilai densitas (m)
\begin{tabular}{|c|c|c|}
\hline \multirow{2}{*}{ No } & \multicolumn{2}{|c|}{ Nilai Densitas } \\
\cline { 2 - 3 } & Densitas(m) & Nilai \\
\hline \multirow{2}{*}{1} & $\mathrm{~m} 1(\mathrm{O}, \mathrm{C})$ & 0.8 \\
& $\mathrm{~m} 1(\Theta)$ & 0.2 \\
\hline 2 & $\mathrm{~m} 2(\mathrm{~W})$ & 0.8 \\
& $\mathrm{~m} 1(\Theta)$ & 0.2 \\
\hline 3 & $\mathrm{~m} 3(\mathrm{O}, \mathrm{C})$ & 0.44 \\
& $\mathrm{~m} 3(\mathrm{~W})$ & 0.44 \\
& $\mathrm{~m} 3(\Theta)$ & 0.2 \\
\hline 4 & $\mathrm{~m} 4(\mathrm{~W})$ & 0.8 \\
& $\mathrm{~m} 1(\Theta)$ & 0.2 \\
\hline 5 & $\mathrm{~m} 5(\mathrm{O}, \mathrm{C})$ & 0.136 \\
& $\mathrm{~m} 3(\mathrm{~W})$ & 0.818 \\
& $\mathrm{~m} 3(\Theta)$ & 0.033 \\
\hline
\end{tabular}

Tabel 6 menunjukkan bagaimana proses perhitungan aturan kombinasi awal sampai aturan kombinasi terakhir berdasarkan gejala yang dipilih, maka dapat disimpulkan bahwa nilai densitas paling tinggi adalah $\mathrm{W}$, yaitu Obsessive Compulsive Disorder tipe Washing dengan nilai densitasnya yaitu $0,818 \times 100 \%=81 \%$.

\section{KESIMPULAN}

Kesimpulan yang dapat diperoleh dari penerapan metode Dempster Shafer untuk diagnosa OCD adalah sebagai berikut:

1. Metode Dempster Shafer dapat digunakan untuk menghitung nilai densitas dari suatu penyakit terhadap gejala.

2. Nilai densitas yang dihasilkan dengan Metode Dempster Shafer mampu memberikan nilai presentasi yang menjadi 
referensi ketepatan diagnosa penyakit Obsessive Compulsive Dissorder.

3. Sistem pakar yang dihasilkan bisa digunakan sebagai sarana diagnosa awal adanya penyakit Obsessive Compulsive Disorder, sehingga penderita bisa secepatnya mendapatkan bantuan dari psikolog.

\section{DAFTAR PUSTAKA}

[1] Lia, Syafaatul, dan Hamidah . 2017. Hubungan Antara Dukungan Sosial dan Obsessive Compulsive Disorder Pada Remaja Putri Dengan Kecenderungan Body Dysmorphic Disorder. Jurnal Psikologi Klinis dan Kesehatan Mental, Volume 06.

[2] Belloch, A., del Valle, G., Morillo, C., \& Carrio, C. 2009. To seek advice or not to keep advice about the problem: the help-seeking dilemma for obsessive compulsive disorder. Social Psychiatry and Psychiatric Epidemiology.

[3] Wang, X., Cui, D., Wang, Z., Fan, Q., Xu, H., Qiu, J., . . Xiao, Z. 2012. Cross-sectional comparison of the clinical characteristics of adults with early-onset and lateonset obsessive compulsive disorder. Journal of Affective Disorder.

[4] Amdan, Prama Y., et all . 2012. Konstruksi Identitas Sosial Penyandang Obsessive Compulsive Disorder. eJournal Mahasiswa Universitas Padjajaran, Volume 01.

[5] Lestari, Endang., dan Emilya . 2017. Sistem Pakar dengan Metode Dempster Shafer Untuk Diagnosis Gangguan Layanan Indihome di PT. Telkom Magelang. Jurnal Ilmu Komputer dan Informatika Volume 03.

[6] Hamid Reza Pourghasemi, Biswajeet Pradhan, Candan Gokceoglu, and Kimia Deylami Moezzi.

[7] A Comparative Assessment of Prediction Capabilities of Dempster-Shafer and Weights-of-Evidence Models in Landslide Susceptibility Mapping Using GIS. Geomatics, Natural Hazards and Risks, vol. 4, no. 2, pp. 93-118, 2013.

[8] Suhendra, I.B. Ramdan, A. Faisal, T.L. Iga, Y. Dewi. 2015. Sistem Pakar Diagnosa Gangguan Sambungan Telepon. Seminar Nasional Teknologi Informasi dan Multimedia di STMIK AMIKOM, Yogyakarta. 